\title{
TROMPE-L'OEIL EM ESTAMPARIA DIGITAL: UM RECURSO PARA ALTERAR A PERCEPC̣ÃO DA SILHUETA MASCULINA
}

Trompe-l'oeil in digital textile printing: a resource to change the perception of the male silhouette

\section{SOUZA , Patrícia de Mello}

Universidade Estadual de Londrina - UEL

patmel@sercomtel.com.br

\section{REIS, Fernando Steinbrenner dos}

Universidade Estadual de Londrina - UEL

fer.stein.brenner@gmail.com

\section{Resumo}

O presente estudo aborda a aplicação da técnica trompe-l'oeil por meio de recursos da estamparia digital, como uma forma de alterar a percepção acerca da silhueta masculina, sem recorrer aos recursos da modelagem. Os resultados experimentais comprovam que os conhecimentos advindos do design gráfico e da arte influenciam e contribuem no processo projetual do design de moda, na medida em que ampliam as possibilidades disponíveis para o desenvolvimento de produtos.

Palavras chave: Estamparia digital. Trompel'oeil. Modelagem. Silhueta.

\section{Abstract}

This study offers an approach on the possibility of employing the trompe-l'oeil technique through digital textile printing resources, in order to change the way the male silhouette is perceived without resorting to patterning techniques. Experimental results prove that graphical design knowledge influences and contributes to the designing process in fashion design, by increasing the available possibilities for product development.

Keywords: Digital textile printing. Trompe-l'oeil. Patterning. Silhouette. 


\section{INTRODUCÃO}

Na moda masculina as discretas mudanças de silhueta através dos tempos marcaram momentos de transformação social. Visto que a vestimenta reflete o contexto sociocultural de cada época, a silhueta masculina acompanha tais mudanças e ainda hoje constitui-se um reflexo da sociedade contemporânea. Aspectos práticos e estéticos influenciam na sua construção. Segundo Buso e Lopes (2010), a definição da silhueta para o homem atual representa a forma de sua apresentação diante da sociedade e o modo particular de se individualizar perante os outros homens. Para Damasceno et al. (2006), há evidências de que a partir dos anos 80 o homem passou a buscar um padrão corporal diferente, que excede o limite da muscularidade com o uso de esteróides e anabólicos, o que se reflete na sua imagem na moda e nas mídias.

Lipovetsky (2003) afirma que mesmo a moda tendo o poder de homogeneizar os gostos e os modos de vida, como os padrões estéticos e de beleza, detecta-se um processo de fragmentação de estilos: na sociedade contemporânea existe uma reivindicação pela individualidade e por liberdades individuais.

Por outro lado, a moda masculina destaca-se não só como expressão da sociedade mas como um importante setor econômico e de inovação tecnológica: segundo dados de 2011 da Associação Brasileira da Indústria Têxtil (ABIT), 47\% dos consumidores de produtos do vestuário são masculinos e este número tende a expandir-se devido ao crescente aumento do acesso à informação pela internet e ao comércio on-line.

Assim, visando a tecnologia e os valores simbólicos dos produtos, o design enquanto processo, importante instrumento para moda atual, vem acrescentando conhecimentos multidisciplinares à construção do vestuário. Conceitos advindos da arte e do design gráfico têm cada vez mais influenciado o desenvolvimento projetual de produtos de moda, ampliando as possibilidades de criação e consumo dos mesmos.

Apesar de distintos em suas definições e às vezes divergentes em suas funções, a moda, a arte e o design possuem fronteiras tênues e cada vez mais extensas. A moda, sendo uma manifestação sociocultural, possui capacidade de agregar aspectos advindos de diferentes vertentes, afinal o produto de moda também é um produto de design e o design se caracteriza por sua multidisciplinaridade de conhecimentos técnicos, científicos e artísticos.

Segundo Martins (2010), o vasto campo de exploração da arte contribui para que determinado produto adquira aspectos conceituais ou comerciais dependendo de como a retórica artística é empregada. É possível se utilizar da 
arte tanto de forma direta sobre um produto por meio de suas formas, cores e aspectos plásticos, como de forma conceitual influenciando o processo de criação em determinada corrente ou obra de arte como uma referência.

Já o design gráfico permeia todo o processo de criação do produto de moda, desde a geração de estampas, até aspectos de divulgação, campanha e ponto de venda. Embora muitas vezes relacionado apenas a estratégias de marketing, o design gráfico pode contribuir intensamente no estilo e criação, tornando-se essencial ao design de moda.

\begin{abstract}
Podemos entender que o design gráfico está intrinsecamente ligado a arte e a arte está ligada ao design gráfico como forma de referência, inspiração e influência e ao mesmo tempo o design gráfico está ligado a moda como agente contribuinte para o produto e comercialização da marca (MARTINS, 2010, p.4).
\end{abstract}

Além das preocupações referentes a aspectos práticos como usabilidade, conforto e adequação ao corpo, o designer de moda ocupa-se com aspectos simbólicos agregados a seus produtos por meio das manifestações artísticas e suas referências. Neste sentido, conforme Leite (2009), um produto de moda vai além das necessidades básicas: possui mensagens cujas informações podem quebrar tradições ou criar códigos em relação ao indivíduo e a sociedade.

Neste contexto, o objetivo deste trabalho é mostrar que a técnica trompeI'oeil, advinda da arte, pode ser aplicada para modificar a percepção sobre a silhueta masculina, utilizando-se da estamparia digital e de seus recursos, auxiliados pelos fundamentos de percepção e sintaxe visual. Para tanto, parte de uma única modelagem plana retangular e obtém outras impressões de silhueta por meio da integração de ferramentas do design gráfico e do design de superfície, projetando graficamente a ilusão criada pelo trompe-l'oeil.

Este estudo, portanto, evidencia, em uma aplicação prática, a proximidade das áreas de arte, design gráfico e design de moda, que apesar de suas especificidades, relacionam-se e complementam-se durante o processo de desenvolvimento do produto.

Considerando a crescente busca por alternativas para atender a um público cada vez mais exigente em relação a produtos que possuam alta tecnologia e valor simbólico, o uso da estamparia digital apresenta diversas vantagens econômicas e a sua aplicação neste trabalho destaca possibilidades de efeitos 
visuais volumétricos que não se restringem às técnicas de modelagem.

\section{ASPECTOS HISTÓRICO SOCIAIS}

$\mathrm{Na}$ história da moda, o modo de intervir sobre a anatomia por meio da silhueta teve significados marcantes socialmente, politicamente e nas relações interpessoais relacionadas à sexualidade e à hierarquia social.

Visto que a moda é uma manifestação sociocultural, afirma-se que a silhueta está intimamente ligada à cultura de cada época e lugar, bem como ao comportamento e as convenções sociais, o que permite revelar a mentalidade de uma época e suas concepções em relação à: sexualidade, movimento, originalidade e fatores relevantes à ideologia daquela sociedade. Desta forma, as transformações sociais nos momentos mais revolucionários da história também correspondem a uma mudança morfológica significativa na silhueta (SALTZMAN, 2004).

A Revolução Francesa, por exemplo, acarretou uma grande mudança nas vestimentas de ambos os sexos: as mulheres se livraram dos espartilhos, crinolinas e tecidos densos e os substituíram por tecidos leves; desestruturaram a forma da cintura e demarcaram os trajes com cortes abaixo do busto. Os homens por sua vez trocaram os trajes excessivamente ornamentados por roupas com materiais e formas semelhantes as do camponês, assumindo uma aparência mais esportiva com características mais funcionais.

No século $X X$, notam-se mudanças mais drásticas em relação à silhueta, inclusive a inclusão de formas femininas no guarda-roupa masculino e viceversa. Com o passar das décadas a figura humana assumiu contornos ora orgânicos, ora geométricos, mas sempre mantendo uma conexão com o contexto sociocultural e político da época.

$\mathrm{Na}$ atualidade, com a globalização e a diversidade de culturas e subculturas vigentes, percebe-se uma enorme quantidade de formas distintas que habitam um mesmo contexto social, resgatando-se, por vezes, formas de décadas passadas.

Todavia, na história da indumentária masculina sempre existiu grande rigidez e poucas foram as mudanças drásticas em relação as formas, já que a elegância estava relacionada a se vestir de forma semelhante aos outros homens. A função de ornamentação da vestimenta da antiguidade foi sendo substituída na era moderna por uma sobriedade e preocupação com a funcionalidade. Foi após a Segunda Guerra Mundial que os estilistas começaram a inserir no guarda roupa masculino novas cores, combinações e modelagens, de maneira 
a expandir a criatividade na hora do vestir, prezando a praticidade e o conforto (BUSO; LOPES, 2010).

Segundo Barros (1997), a roupa e a silhueta são responsáveis pela apresentação de cada indivíduo na sociedade e pela impressão que causam. O homem contemporâneo acompanha os padrões de beleza preocupando-se com a saúde do corpo e buscando formas idealizadas. Logo, a silhueta trapezoidal ou a triangular invertida, configurações representativas da estrutura muscular masculina buscada nas academias, são consideradas ideais por conferirem maior ênfase aos ombros.

\begin{abstract}
Homens adultos e adolescentes também ficam sujeitos a imagens da mídia que descrevem a forma de um corpo ideal: mesomórfico, com ombros largos, maior desenvolvimento da parte de cima do corpo - peitorais, dorsais e braços - e quadris estreitos (DAMASCENO et al., 2006, p. 84).
\end{abstract}

Do mesmo modo que para as mulheres o padrão de beleza define a silhueta de cintura marcada, em que o busto e o quadril são acentuados, como sendo ideal.

\begin{abstract}
As pessoas em geral, e as mulheres jovens em particular, tentam se amoldar ao ideal de beleza dominante. A deformação e a reformulação do corpo por meio de roupas modeladoras, enchimentos ou faixas têm alterado as silhuetas da moda ao longo das eras. (JONES, 2011, p. 27).
\end{abstract}

Esta preocupação extrema por atingir o corpo ideal tem ocasionado uma metamorfose constante, inclusive no segmento masculino, com o aumento das intervenções cirúrgicas e a maior busca por tratamentos estéticos. Assim sendo, a silhueta adotada por cada indivíduo também é um reflexo de como ele deseja que seu corpo seja apresentado à sociedade.

Ao mesmo tempo em que a roupa é capaz de fazer com que o homem torne-se parte de um determinado grupo social ou adepto de um estilo, também possui o poder de individualizá-lo ou destacá-lo perante os outros. 


\section{A SILHUETA COMO FORMA}

A silhueta é o contorno geral de uma figura ou a sua representação delimitada de modo uniforme como uma sombra (WEISZFLOG, 2004). É um termo bastante utilizado na moda para se referir ao formato de determinada peça - seu shape: refere-se ao contorno do produto que envolve o corpo que o sustenta.

Sorger e Udale (2009) afirmam que a silhueta é a primeira impressão que se obtém de uma roupa, uma vez que é possível visualizá-la de forma global desde o primeiro contato visual. Segundo Saltzman (2004) o conceito de silhueta implica em uma representação bidimensional; para Jones (2011) tal representação significa ver a roupa à distância sem que os detalhes sejam percebidos.

Quando se considera a indumentária, contudo, não basta atentar para a silhueta: deve-se considerar também os aspectos tridimensionais que são de grande importância. Afinal, existe uma dimensão espacial entre o têxtil e o corpo, e sua configuração se modifica se vista de frente, de perfil ou em movimento. A partir da construção da vestimenta é possível prolongar morfologicamente as linhas da anatomia e assim modificar o esquema corporal e suas proporções.

Assim, o termo está ligado à relação que se estabelece entre o contorno real do corpo e a capacidade que a vestimenta tem de modificá-lo ou delimitá-lo, sendo que é a partir da silhueta e dos elementos construtivos que se consegue acentuar ou atenuar determinada parte do corpo.

A construção da vestimenta é obtida pelo processo da modelagem, que consiste na transposição de um projeto representado de forma bidimensional em um artefato de qualidades tridimensionais. Assim, segundo Jones (2011), a amplitude e o volume, ou a falta destes, passam a ser visíveis na silhueta da roupa. Um dos fatores responsáveis pela definição do volume é a rigidez ou fluidez do material têxtil empregado ao modelo. Para Saltzman (2004), tecidos mais estruturados tendem a formar volumes e silhuetas mais geométricas, com contornos rígidos; tecidos mais fluidos insinuarão mais as formas do corpo obtendo um contorno mais suave; e materiais aderentes desenham as formas do corpo em sua plenitude.

Segundo Heinrich (2005), a construção da modelagem baseia-se nos volumes e reentrâncias da forma anatômica, ou seja, é pela modelagem que são decididas as partes do corpo a serem destacadas ou preteridas por meio da silhueta e da linha formada por seus aspectos construtivos. Para Sorger e Udale (2009), a linha da roupa refere-se ao efeito visual que se obtém a partir do corte, das costuras, das pences e a intenção em guiar o olhar de forma a 
alongar, achatar, expandir ou comprimir a anatomia. Neste sentido, a utilização das linhas na construção das peças ou através do design de superfície - por meio de recursos gráficos como a estamparia - possibilita a manipulação do olhar a fim de que se obtenha uma impressão de silhueta diferente da real. Este efeito de ilusionismo é chamado de trompe-l'oeil.

\section{O TROMPE-L'OEIL}

O trompe-l'oeil - que vem do francês, enganar o olho - é advindo da arte e possui grande relação com o ilusionismo. Segundo Regiani (2008), é difícil defini-lo em virtude da polissemia de seu significado, contudo, é possível identificar seus efeitos em diversos segmentos da arte e do design. Apesar da expressão ter sido popularizada no século XIX, pelo barroco, registros apontam para um surgimento muito mais antigo, que remonta ao século $\vee$ a.C.

O Dicionário de Termos Artísticos (1998) apresenta uma definição de trompe-l'oeil com riqueza de características:

Estilo de pintura no qual a imagem é representada com um intencional grau de detalhes realísticos, conseguido graças ao uso do claro-escuro, com o propósito de iludir o espectador, levando-o a pensar que se trata de algo real, em três dimensões. É utilizado em uma grande gama de trabalhos, inclusive em decorações arquitetônicas de grandes dimensões, que tem por objetivo alterar a percepção de quem as vê quanto ao verdadeiro tamanho do espaço em que se encontram (MARCONDES, 1998, p. 282).

Trata-se, portanto, de um recurso de caráter ilusionista que consiste em enganar ou iludir a visão. A intenção do trompe-l'oeil é de fazer com que o espectador pense estar diante de um objeto real e não de uma imagem. Para isso são fundamentais as relações estabelecidas pela sintaxe da linguagem visual e pelo estudo da percepção visual realizado pela Escola Gestalt.

As leis definidas pelos estudos da Gestalt referem-se ao conjunto de fundamentos que permeiam o fenômeno da percepção visual. Segundo Gomes (2004) o que acontece em nosso cérebro é diferente do que acontece em nossos olhos: "A excitação cerebral não se dá em pontos isolados, mas por extensão. Não existe, na percepção da forma, um processo posterior de associações das várias sensações. A primeira sensação já é de forma, já é global e unificada." 
(GOMES, 2004, p. 19)

Seja na arte, na arquitetura, no design gráfico, de produto ou moda, o uso das teorias da Gestalt se pautam no princípio da pregnância da forma. Ou seja, existe a necessidade de se obter imagens ou produtos nos quais fatores como equilíbrio, clareza e harmonia visual sejam levados em consideração para uma composição visual unificada.

Uma das propriedades conceituadas pela Gestalt e fundamental para a constituição do trompe-l'oeil é a de forma como volume, o qual pode ser obtido por meio de artifícios nas técnicas de representação, ou seja, através do desenho ou pintura, utilizando luzes, brilhos, sombras e texturas para se obter a sensação de espessura ou profundidade. Também é possível visualizar a tridimensionalidade em um desenho em perspectiva, pois ilustra a dimensão por meio de uma superfície plana (GOMES, 2004).

Outro elemento importante é o contraste figura/fundo. O olhar humano sempre destaca uma figura central em relação ao seu entorno, o fundo, e é exatamente a partir disso que a mente estabelece a noção de um contorno geral, ou silhueta (LUPTON, 2008)

Um dos fatores de suma importância é a cor. Segundo Lupton (2008), a cor tem a capacidade de destacar ou preterir algo, da mesma forma que serve para diferenciar, conectar, ressaltar e esconder.

Esta integração entre ilusões de volume, contrastes e cores dá base ao trompe-l'oeil, o qual pode ser utilizado em muitas áreas. $\mathrm{Na}$ arquitetura, por exemplo, é empregado como forma de alterar a percepção em relação à dimensão de determinado espaço. Foi aplicado em grandes painéis nos tetos de capelas a fim de dar a sensação de proximidade com o céu.

Hoje o recurso é usado em biombos que cercam obras ainda inacabadas onde uma representação bidimensional do projeto dá a sensação da obra finalizada. É como uma simulação da ocupação da construção na paisagem. Um dos expoentes na utilização do trompe-l'oeil integrado à arquitetura é o designer iraniano Mehdi Ghadyanloo, que utiliza pinturas realistas sobre fachadas e muros, criando ilusões de ambientes inexistentes no cotidiano urbano.

No design de moda a técnica é aplicada sobre a vestimenta com a intenção de criar efeitos ópticos e enganar o olhar quanto à morfologia do corpo e suas proporções, o que se reflete na silhueta do produto. Por meio de linhas construtivas que delimitam planos e os efeitos gerados por estes, obtém-se uma ilusão em relação à forma, demarcando partes do corpo com o efeito de 
cintura mais fina, ombros mais largos, quadril mais amplo entre outros.

Assim, por meio do trompe-l'oeil é possível enganar a relação de contorno real, criando a sensação de uma silhueta percebida ou silhueta trompe-l'oeil, partindo-se de diferentes aspectos: diferenças de contrastes obtidos pela cor; de volumes decorrentes da incidência de luz, sombra ou textura; de profundidade resultante da perspectiva.

Os efeitos podem ser obtidos de inúmeras maneiras: com blocos de cores sobre fundos neutros; diferentes texturas e materiais têxteis; com costuras que estabeleçam formas que conduzam o olhar a determinadas partes do corpo criando uma perspectiva; ou ainda de forma bidimensional por meio da estamparia aplicada ao plano geral da peça.

Analisando os efeitos da técnica sobre a indumentária, destaca-se a busca por adequar o corpo a uma imagem ou padrão de beleza - mais alto, mais magro, mais curvilíneo - tanto por modificar sua morfologia, como por causar estranhamento com a expectativa por uma forma e sua não concretização, já que ela é apenas uma representação.

Sua função muitas vezes é de simular ou destacar costuras e pences e desta forma acrescentar representações de volumes em áreas planas. Elsa Schiaparelli (1890 - 1973), que se vincula a movimentos artísticos do início do século $X X$, inseriu conceitos do cubismo e do surrealismo em suas coleções. Utilizou-se da técnica como forma de substituir laços, bolsos e golas por representações bidimensionais. Era uma maneira de simplificar a forma sem perder a ornamentação e a feminilidade.

Mary Katrantzou, designer contemporânea, apresenta em suas coleções um trompe-l'oeil bastante detalhado, utilizando imagens realistas da arquitetura - sua grande referência - do design e da fotografia, para criar roupas que iludem o olhar. A eficiência de sua técnica deve-se ao emprego da estamparia digital sobre tecidos, o que torna as imagens cada vez mais nítidas sobre as peças.

\section{ESTAMPARIA DIGITAL}

A estamparia digital refere-se ao processo de impressão inkjet sobre substrato têxtil, por meio da transmissão de informações referentes ao desenho no computador diretamente para os cabeçotes de impressão (NEIRA, 2009).

$\mathrm{Na}$ década de 80 surgiram os primeiros processos de digitalização da estamparia com o aparecimento dos softwares gráficos que substituíam o desenho manual pelo digital. As impressoras, com tecnologia ainda precária, 
baixa velocidade e alto custo de insumos tornavam os produtos onerosos.

Com o desenvolvimento tecnológico na área e a constatação dos benefícios da estamparia digital, a indústria conseguiu aprimorar as impressoras até que sua velocidade e qualidade de imagem tornassem a técnica popular, uma alternativa eficaz na elaboração de produtos com exclusividade e grande apelo gráfico.

Segundo Neira (2009), a economia de energia, água, corantes e pigmentos, e o melhor tratamento dos efluentes são diferenciais relacionados a aspectos ambientais oferecidos pela técnica. Da mesma forma, se analisadas as questões que se referem à criação, a superioridade do processo é absoluta. Trata-se de uma impressão por policromia, portanto, os desenhos não possuem um limite de cores ou de repetição, os encaixes são mais precisos e a elaboração de variantes é infinita, além de possibilitar amostragem instantânea.

Em relação à organização do trabalho na indústria, com a introdução da estamparia digital houve modificações relacionadas ao fluxo do processo, que elimina procedimentos intermediários de revisão e acerto de desenhos, pois os ajustes são feitos de forma digital.

Em um mercado cada vez mais sedento por inovação e por personalização, esse tipo de estamparia se configura como um bom negócio já que atende a um novo conceito de produto-consumo, chamado por Tippet de customização em massa (NEIRA, 2009).

Para o trompe-l'oeil, a utilização de scanners de captura de imagens tridimensionais de grande formato unidos à estamparia digital tem permitido que imagens cada vez mais realistas sejam transformadas em produtos do vestuário.

Contudo, a técnica não deve ser entendida apenas como uma maneira de ampliar soluções, mas sim como modo de possibilitar novas expressões plástico-formais no produto do vestuário, colaborando para novas descobertas e experiências visuais.

Nas atuais semanas de moda é fácil encontrar exemplos da utilização da técnica em diversos suportes e em diversos estilos, o que demonstra a versatilidade e a flexibilidade do processo. A moda masculina ainda se mostra mais pontual e menos exuberante que a moda feminina devido a certa resistência do grande público em ousar no vestir. Entretanto, a demanda por esses produtos tem aumentado gradativamente. 


\section{APLICACCÃO E EXPERIMENTACC̃̃O}

Para o cumprimento dos objetivos propostos neste estudo, uma fase de experimentação sucedeu o levantamento bibliográfico inicial, que serviu de base para a sequência do trabalho.

Estabeleceu-se que as experimentações - aplicação das estampas seriam realizadas sobre uma peça tridimensional vestível, composta por base geométrica retangular, desenvolvida por meio da modelagem plana. A impressão visual causada pela estampa seria a única responsável por alterar a percepção sobre a silhueta real do usuário.

Então, utilizou-se uma modelagem plana de blusa de contorno retangular como suporte para a criação de estampas que deveriam preencher todo o molde frontal da peça e remeter a outras silhuetas sem a utilização de elementos construtivos de modelagem, como pences e costuras.

Desenvolveu-se quatro estampas distintas, com o intuito de apresentar a oposição entre a silhueta considerada ideal masculina - a triangular invertida; a fora do padrão: oval - e as silhuetas consideradas ideais para o feminino ampulheta e violão.

A decisão de utilizar silhuetas já conhecidas e de significado histórico deu-se pelo fato da fácil identificação para sua validação posterior, ou seja, seria evidente a impressão visual causada pela imagem sobre a silhueta real retangular da peça vestida.

Primeiramente as silhuetas foram desenhadas sobre o molde plano no software Adobe Photoshop sem cor, com ênfase somente para o contorno. Com a utilização do preto delinearam-se planos chapados sobre o fundo branco. Imediatamente a percepção visual remetia a forma desenhada à silhueta escolhida. Este mesmo processo costuma ser realizado em quadros retangulares pretos com planos - silhuetas - em branco, causando efeito semelhante.

Assim, torna-se possível avaliar meios de se aplicar composições visuais mais elaboradas sobre o retângulo, de forma a explorar e demonstrar a capacidade da estamparia digital.

O caráter artístico agrega-se as estampas que foram desenvolvidas com referência nas obras do artista mexicano Curiot, que mistura cores vibrantes a elementos do folclore do México preenchendo telas de acrílico e muros com criaturas imaginárias. Ele modifica a paisagem real com seres mitológicos e adiciona cor ao ambiente urbano cinzento. A cartela de cores definida para as estampas remete a uma das obras do artista, mostrada na Figura 1, que integra 
a exposição Age of Omuktlans .

Figura 01 - Obra do artista mexicano Curiot.

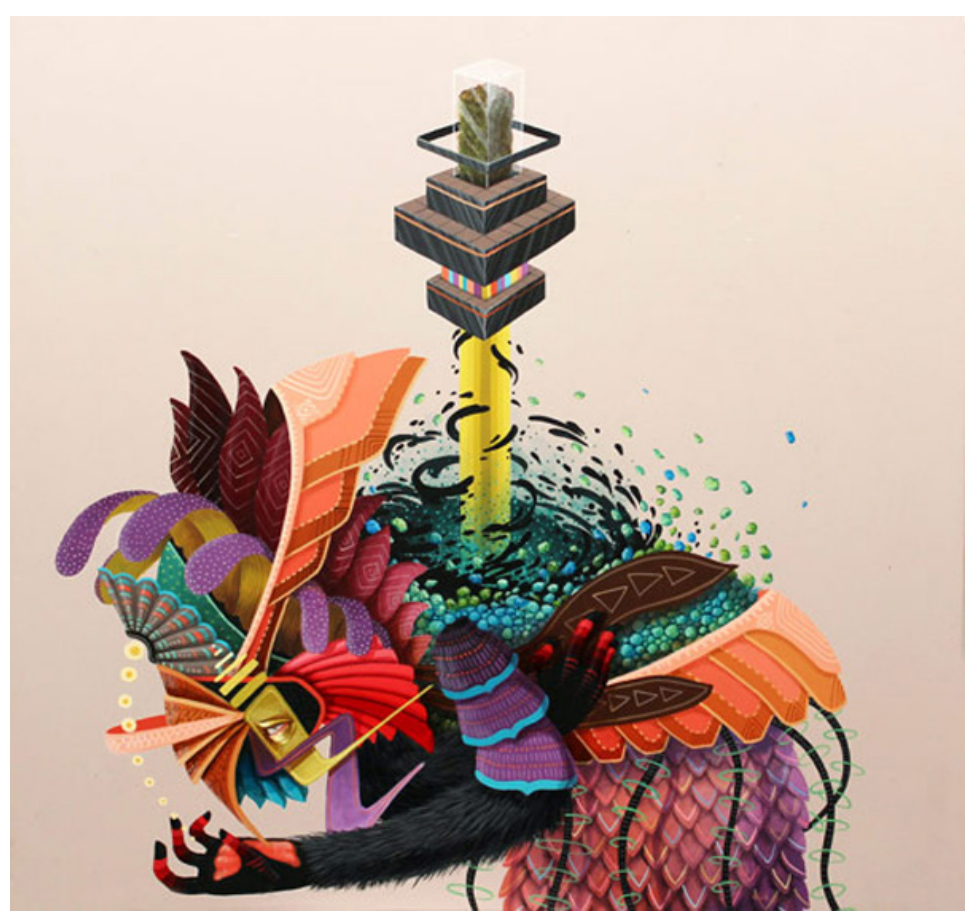

Fonte: Martins (2014).

As imagens foram todas espelhadas a fim de que a simetria fosse preservada e mantivesse a fidelidade com as silhuetas propostas. Foram utilizadas vinte fotografias e cerca de sete texturas diferentes para criar as composições sobre fundo negro. Por fim, antes de configurar o arquivo para impressão criou-se uma camada sobre a composição simulando as sombras de contorno do corpo como forma de tornar ainda mais vívida a impressão de volume sugerida pelas imagens.

Realizaram-se três testes em diferentes tecidos, em empresas especializadas, antes da impressão final para a confecção dos protótipos. Os primeiros dois testes apresentaram problemas em relação à nitidez da imagem e à fidelidade das cores. A cor que apresentou maior dificuldade de fidelidade, devido a diferenças na calibragem de máquinas e diferentes substratos testados, foi o preto. Somente no terceiro teste foi obtido um resultado satisfatório sendo assim realizado o pedido de prototipagem.

Os protótipos em tamanho real foram impressos pela empresa DTPrint Estamparia Digital situada na cidade de São Paulo. A empresa com vasta experiência nesse tipo de serviço apresentou completa fidelidade à imagem enviada. A arte final continha as seguintes configurações: $57 \mathrm{~cm} \times 83 \mathrm{~cm}, 4$ cores, 72 dpi de resolução em Jpeg. 
O tecido escolhido como suporte foi a sarja acetinada em 100\% poliéster. Uma das especificações do tipo de equipamento utilizado pela DTPrint para estamparia digital é que quanto maior a porcentagem de poliéster na fibra têxtil maior a saturação das cores e maior a fixação da estampa.

O conjunto de estampas deu origem a coleção INLUSIO, do latim ilusão, caráter essencial do trompe-l'oeil, mostrada nas Figuras 2, 34 e 5.

Figura 02 - Estampa da coleção INLUSIO representando silhueta triangular invertida
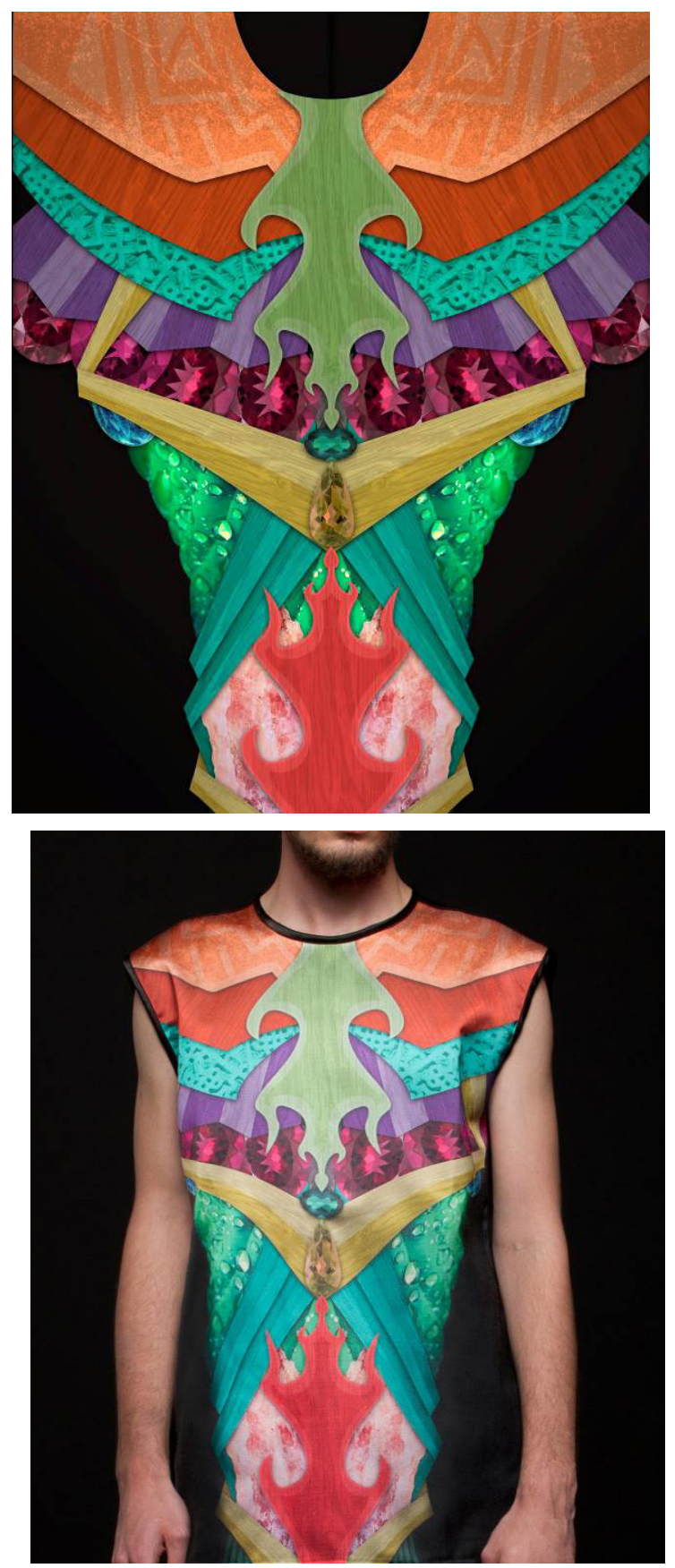

Fonte: Própria, 2013. 
Figura 03 - Estampa da coleção INLUSIO representando silhueta ampulheta.
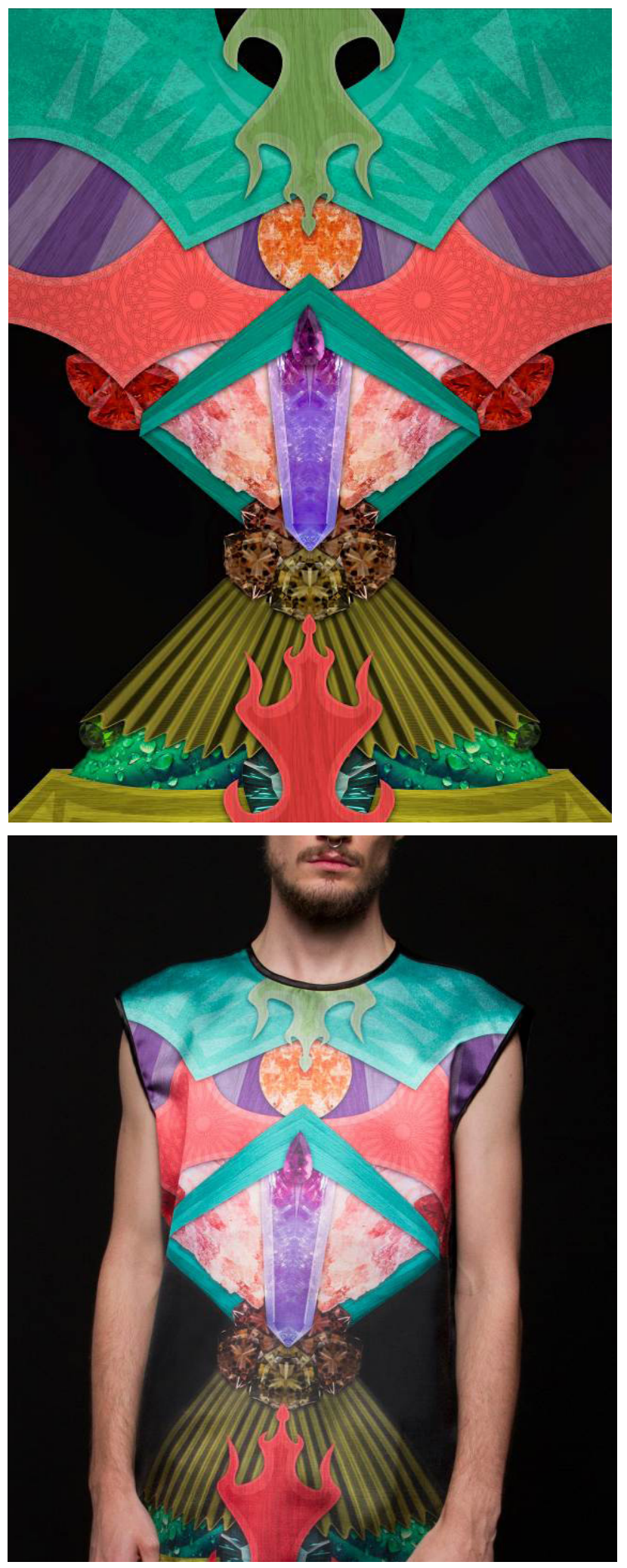

Fonte: Própria, 2013. 
Figura 04 - Estampas da coleção INLUSIO representando a silhueta oval
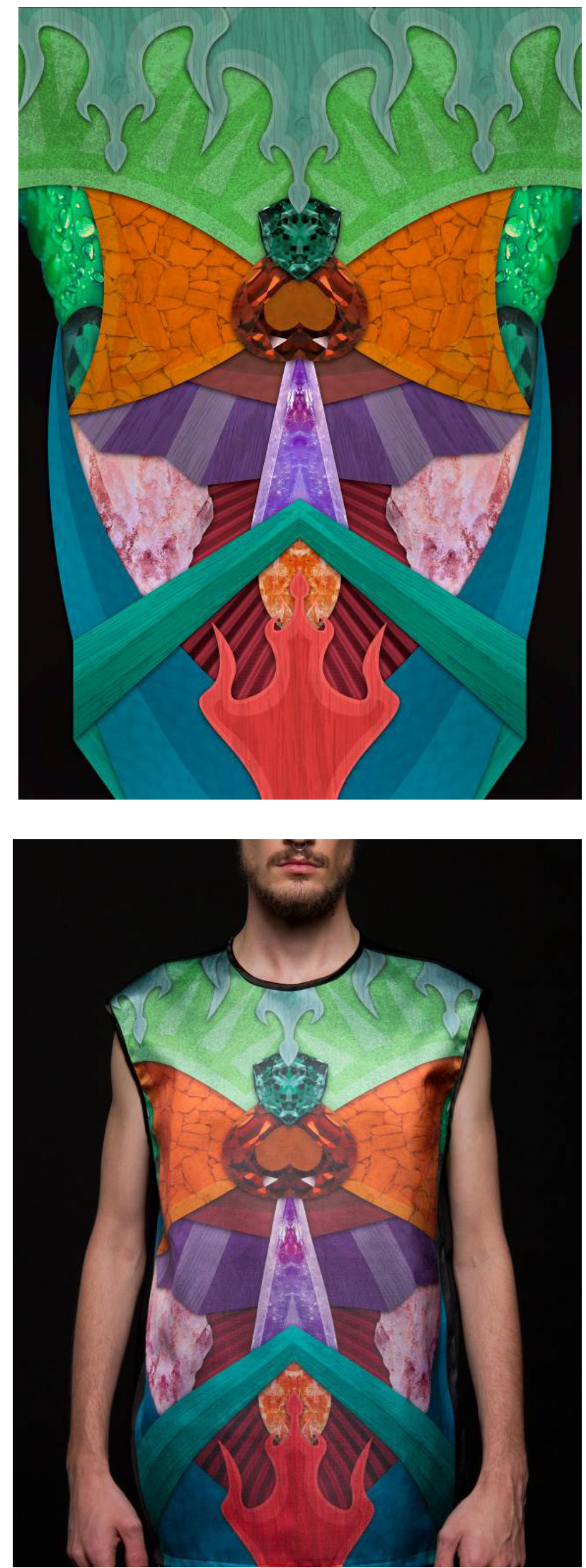

Fonte: Própria, 2014. 
Figura 05 - Estampa da coleção INLUSIO representando silhueta violão.

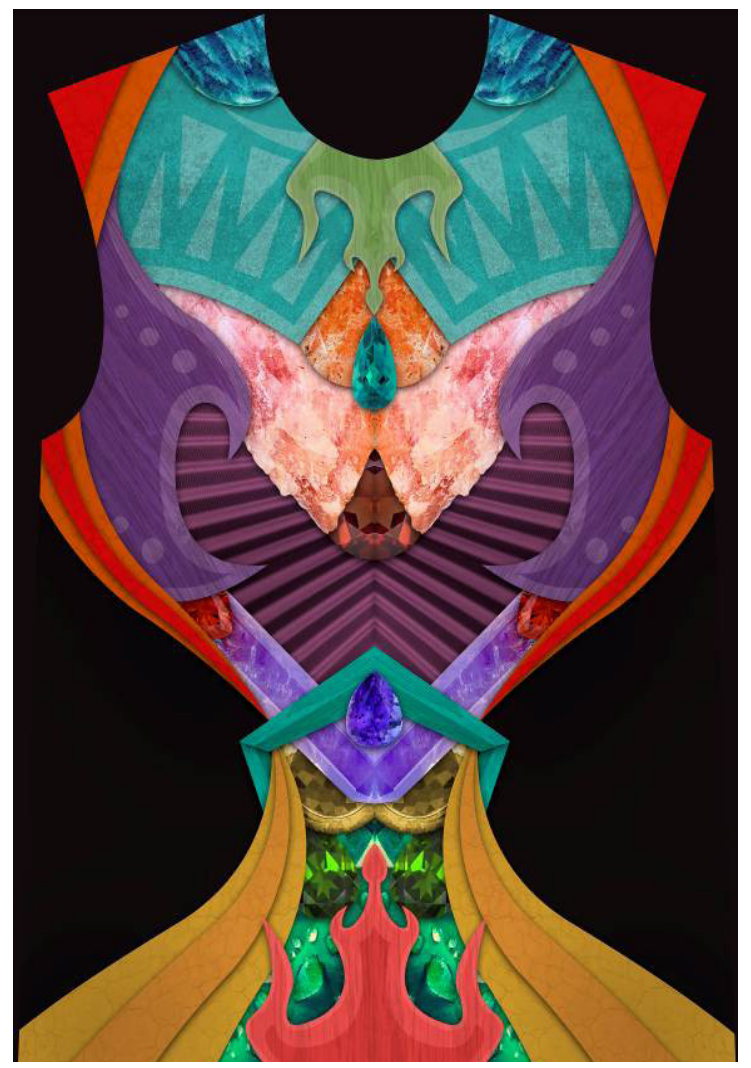

Fonte: Própria, 2014.

\section{CONSIDERAC ÕES FINAIS}

A experimentação viabilizou a aplicação da técnica trompe-l'oeil por meio da estamparia digital sobre peças do vestuário masculino. Comprova-se que a técnica em questão apresenta recursos relevantes para a construção da linha da roupa e influencia consideravelmente a percepção sobre a silhueta. Sob tais constatações, pode-se afirmar que a união do trompe-l'oeil com os recursos das modelagens tridimensional e bidimensional podem resultar em efeitos visuais ainda mais complexos e elaborados.

Da mesma forma, a estamparia digital apresenta inúmeros benefícios em relação ao gasto energético do processo e à rapidez de impressão e fixação da imagem no substrato. Considerando o resultado final das estampas podese afirmar que o processo possui fidelidade à imagem gerada digitalmente e alcança gama infinita de cores e tons sem grande dificuldade, se respeitadas as especificações de cada equipamento e substrato.

Este estudo utilizou as obras do artista mexicano Curiot como referência de composição visual e, de forma indireta, aproximou conceitos de arte, design gráfico e moda. Nesta integração, ressalta-se que o design gráfico permeou 
todo o processo desde a criação das silhuetas até a arte finalização de cada estampa, sendo um instrumento de suma importância para a criação de produtos de moda. Por outro lado, no trajeto da pesquisa foi entendido que o desejo gerado em torno de um determinado produto de moda está ligado aos aspectos simbólicos atribuídos ao mesmo, como uma forma de identificação e individualização.

Entretanto, apesar dos pontos positivos levantados, a estamparia digital no Brasil ainda é um processo novo, o que aumenta o custo em sua execução. Dessa forma, torna-se restrito a grandes indústrias que conseguem baratear o recurso pelo aumento do número de unidades impressas. Falta incentivo fiscal e da própria indústria para que a tecnologia mais avançada chegue ao país de forma acessível a todo tipo de empresa do setor.

Neste contexto, o presente trabalho convida estudiosos do design gráfico e da moda a prosseguirem os estudos sobre o processo de estamparia digital em experimentações em diversos segmentos para fomentá-la em território nacional e ampliar a sua aplicação na indústria.

\section{REFERÊNCIAS}

ASSOCIAÇÃO BRASILEIRA DA INDÚSTRIA TÊXTIL (ABIT). Disponível em: <http://www.abit.org.br>. Acesso em: 28 jun. 2013.

BARROS, Fernando de. Elegância: como o homem deve se vestir. São Paulo: Negócio, 1997.

\section{BUSO, Vanessa Zanardo; LOPES, Talita Cristina. A Modelagem para a} construção da identidade masculina. In: COLÓQUIO DE MODA, 6., 2010, São Paulo. Anais... São Paulo: UAM, 2010.

DAMASCENO, Vinicius Oliveira; VIANNA, Viviane Ribeiro Ávila; VIANNA, Jeferson Macedo; LACIO, Marcio; LIMA, Jorge Roberto Perrout; NOVAES, Jefferson Silva. Imagem corporal e corpo ideal. Revista Brasileira de Ciência e Movimento, Brasília, v. 14, n. 1, p. 87-96, 2006.

GOMES FILHO, João. Gestalt do objeto: sistema de leitura visual da forma. São Paulo: Escrituras, 2000.

\section{HEINRICH, Daiane Pletsch. Modelagem e técnicas de interpretação para} confecção industrial. Novo Hamburgo: Feevale, 2005.

JONES, Sue Jenkin. Manual do estilista. 3 ed. São Paulo: Cosac Naify, 2011. 
LEITE, I. T. R. A informação visual no design de moda e a influência na construção da identidade de gênero: dimensões sociais e culturais. In: COLÓQUIO DE MODA, 5., 2009, Recife. Anais... Recife: FBV, 2009.

LIPOVETSKY, Gilles. O império do efêmero: a moda e seu destino nas sociedades modernas. São Paulo: Companhia das Letras, 2003.

LUPTON, Ellen. Novos fundamentos do design. São Paulo, Cosac Naify, 2008.

MARCONDES, Luiz Fernando Cruz. Dicionário de termos artísticos. Rio de Janeiro: Pinakotheke, 1998.

MARTINS, Eloise. Curiot e os monstros. Disponível em: <http://www.ideafixa. com/curiot-e-os-monstros/.>. Acesso em: 10 dez. 2014.

MARTINS, Thaiza Caldeira. Moda, arte e design gráfico: uma construção estratégica. In: COLÓQUIO DE MODA, 6., 2010, São Paulo. Anais... São Paulo: UAM, 2010.

NEIRA, L. G. Estamparia digital: a última impressão é $a$ que fica! In: COLÓQUIO DE MODA, 5., 2009, Recife. Anais... Recife: FBV, 2009.

REGIANI, Atila Ribeiro. Trompe l'oeil: reflexões sobre a arte contemporânea. 2008. Dissertação (Mestrado em Artes Visuais) - Centro de Artes, Universidade do Estado de Santa Catarina, Florianópolis, 2008.

SALTZMAN, Andrea. El cuerpo diseñado: sobre la forma en el proyecto de la vestimenta. Buenos Aires: Paidós, 2004.

SORGER, Richard; UDALE, Jenny. Fundamentos de design de moda. Porto Alegre: Bookman, 2009.

WEISZFLOG, Walter. Michaelis. Moderno Dicionário da Língua Portuguesa. São Paulo, 2004. 